\title{
Fitness and Competitive Ability of an Azoxystrobin-Resistant G143A Mutant of Magnaporthe oryzae from Perennial Ryegrass
}

\author{
B. Ma and W. Uddin, Department of Plant Pathology, Pennsylvania State University, University Park 16802
}

\begin{abstract}
Ma, B., and Uddin, W. 2009. Fitness and competitive ability of an azoxystrobin-resistant G143A mutant of Magnaporthe oryzae from perennial ryegrass. Plant Dis. 93:1044-1049.

Development of azoxystrobin resistance in Magnaporthe oryzae from perennial ryegrass has been reported in certain locations in the United States, and possible development of resistance in additional areas is a major concern in the golf course industry. The study was undertaken to evaluate the relative fitness and competitive ability of a field-collected azoxystrobin-resistant G143A mutant by comparing it with a wild-type strain using detached perennial ryegrass blades. A fitness comparison experiment indicated that the disease severity of the wild-type strain was significantly higher than that of the mutant; however, the mutant produced greater secondary inoculum. When inoculated with three mixed populations of resistant and wild-type strains at different ratios, the production of conidia by the wild-type strain increased and that of the mutant decreased after infection occurred in all three populations tested. In an experiment on the effect of various fungicides on the population initially containing $5 \%$ of the mutant, preventive application of azoxystrobin allowed 5\% of the mutant to dominate the population after the infection. However, other non-quinone outside inhibitor fungicides and mixtures of azoxystrobin with contact fungicides eliminated the entire mutant. This study demonstrates that the wild-type strain of $M$. oryzae has a competitive advantage over the mutant within the environment tested. Mixtures and alternations of fungicides with different modes of actions may prevent rapid build-up of resistance in the gray leaf spot pathosystem.
\end{abstract}

Gray leaf spot, caused by Magnaporthe oryzae B. C. Couch (anamorph Pyricularia oryzae Cavara), is a serious disease of perennial ryegrass (Lolium perenne L.) turf. The disease is chiefly managed by chemical approaches, including use of various classes of systemic and contact fungicides. Quinone outside inhibitors (QoIs) such as azoxystrobin have been effectively used to manage gray leaf spot in the golf course industry. Development of resistance by $M$. oryzae to azoxystrobin was first detected in 2000 (28), probably due to intensive use of the compound at the same location. In development of resistance in the $M$. oryzae population, two point mutations, G143A and F129L in cytochrome $\mathrm{b}$ of mitochondria, are known to occur at the target site (15). The G143A mutation reportedly carries a high level of resistance, which renders the fungicide completely ineffective. On the other hand, a much lower level of resistance carried by the F129L mutation does not necessarily affect field performance of QoI fungicides in many cases (Fungicide Resistance Action Committee, www.frac.info). To date,

Corresponding author: W. Uddin

E-mail:wxu2@psu.edu

Accepted for publication 26 June 2009.

doi:10.1094/PDIS-93-10-1044

(C) 2009 The American Phytopathological Society experimental work on resistance in $M$. oryzae to QoIs has focused on the molecular and biochemical aspects of the fungicide resistance $(1,3,10,13,16)$; very little is known about the dynamics of resistance at the population level.

The dynamics of competition between fungicide-resistant and -sensitive strains determines whether or not resistance becomes established in the pathogen population $(11,21)$. In recent years, empirical studies have demonstrated varying outcomes of such competition. In a study on the dynamics of carbendazim resistance in eyespot fungi (Tapesia yallundae Wallwork \& Spooner and T. acuformis (Boerema, R. Pieters \& Hamers) Crous on winter wheat), a stable coexistence of about $50 \%$ of carbendazim-resistant and sensitive strains on carbendazim-treated plots between 1987 and 2000 was observed (5). However, in a study on Botrytis cinerea Pers. affecting geranium, the dicarboximide-resistant isolate completely replaced the sensitive strain after two applications of vinclozolin whereas the resistant isolate remained at the initial level of $0.02 \%$ of the population in the absence of vinclozolin (26). Studies on QoIs in different pathosystems indicated that the competition between resistant and sensitive strains varied. In a study on powdery mildew of wheat, caused by Blumeria graminis (DC.) Speer f. sp. tritici, the initial 10\% QoI-resistant population of the pathogen reportedly increased to 20 to
$35 \%$ of the total population and remained steady on untreated host tissue over three generations (7). In contrast, in a study on downy mildew of grapes, the QoI-resistant population of Plasmopara viticola (Berk. \& M. A. Curtis) Berl. \& De Toni failed to increase in the pathogen population in a cycling experiment (12).

The outcomes of competition between a resistant and a wild-type strains is largely determined by their fitness in the absence of fungicide $(8,9,21,22)$. Studies on QoI resistance mutations in cytochrome $\mathrm{b}$ of Saccharomyces cerevisiae Meyen ex E. C. Hansen revealed that most mutations were accompanied by functionally impaired mitochondria which have reduced electron flow through the cytochrome $b c 1$ complex (16); therefore, it has been suspected that QoI-resistant strains may suffer from fitness penalties. A laboratory G143A mutant of Venturia inaequalis (Cooke) G. Winter returned to a sensitive stage in the absence of fungicide is also an indication of such fitness penalties (32). Further evidence of the fitness penalty was observed for a G143A mutant of Ustilago maydis (DC.) Corda. The mutation had significant adverse effects to the fungus during growth in liquid culture and infection on young corn plants (33). However, the G143A mutation does not adversely affect the fitness of all pathogens. For example, no fitness penalty was found in a spontaneous G143A mutant of $B$. graminis $(7,12)$. Laboratory-selected G143A and G143S mutants of $M$. grisea, pathogenic on goosegrass (Eleusine indica (L.) Gaertn.), weeping lovegrass (Eragrostis curvula (Schrader) Nees), and barley (Hordeum vulgare $\mathrm{L}$.), also did not show differences in either the saprophytic stage or pathogenic development compared with a wildtype strain (2).

It is unclear whether fitness penalties exist in the G143A resistant field mutant of $M$. oryzae in the gray leaf spot pathosystem. Considering the importance of resistance management in the early stage of resistance development, it is important to understand the dynamics of a small portion of resistant mutants of $M$. oryzae in a pathogen population in the absence and presence of commonly used fungicides for gray leaf spot control. Therefore, this study was undertaken to (i) evaluate the relative fitness associated with the G143A mutant of $M$. oryzae in the gray leaf spot pathosystem, (ii) determine the competitive relationship between resistant and wild- 
type strains in the turf canopy in the absence of fungicide, and (iii) determine the effects of various classes of fungicides on a population initially containing $5 \%$ of the G143A mutant.

\section{MATERIALS AND METHODS}

Plant materials, strains, and production of conidia. Perennial ryegrass (Legacy II) plants were grown from seed in plastic pots $(10 \mathrm{~cm}$ in diameter; Stuewe \& Sons, Inc., Corvallis, OR) that were filled to $1 \mathrm{~cm}$ below the rim with granular calcined clay medium (Turface MVP; Allied Industrial Material Corp., Buffalo Grove, IL), in a greenhouse maintained at 21 to $24^{\circ} \mathrm{C}$ and a $16-\mathrm{h}$ photoperiod with supplemental light provided by a $400-W$ Metal Halide Lamp (Ruud Lighting, Racine, WI). Plants were watered daily and fertilized once a week with a water-soluble fertilizer $\left(20 \% \mathrm{~N}, 20 \% \mathrm{P}_{2} \mathrm{O}_{5}\right.$, and $20 \% \mathrm{~K} ; 1.3 \mathrm{~g} /$ liter of water). Grasses were trimmed twice a week and maintained at a $7.5-\mathrm{cm}$ height until they were 4 weeks old.

A wild-type strain and a G143A azoxystrobin-resistant mutant of $M$. oryzae were selected for this experiment. The wild-type strain was collected in 2000 from a perennial ryegrass fairway at Willow Hollow Golf Course near Leesport, PA, where no QoIs were reportedly used. The G143A mutant was also collected in 2000 from a fairway at Griffin Gate Golf Course in Lexington, KY, where an azoxystrobin control failure was reported (27).

Production of conidia for both isolates was produced using the following procedure. An approximately $2-\mathrm{mm}^{2}$ piece of filter paper, on which $M$. oryzae had been stored at $-80^{\circ} \mathrm{C}$, was placed on potato dextrose agar (PDA; $39 \mathrm{~g}$ of Difco PDA agar in 1 liter of distilled water) and incubated at $22^{\circ} \mathrm{C}$ for 5 days. PDA blocks ( 5 $\mathrm{mm}^{3}$ ) containing the actively growing mycelium were removed and placed on oatmeal agar amended with perennial ryegrass extract ( $20 \mathrm{~g}$ of Difco agar and $20 \mathrm{~g}$ of Gerber oatmeal in 1 liter of diluted perennial ryegrass tea) for greater sporulation. Perennial ryegrass extract was prepared by boiling $20 \mathrm{~g}$ of fresh perennial ryegrass leaf blades in 1 liter water for $10 \mathrm{~min}$; then, ryegrass extract was diluted twofold by adding an equal volume of distilled water. The plates were sealed with Parafilm (Pechiney Plastic Packaging, Menasha, WI) and incubated at $26^{\circ} \mathrm{C}$ under 12-h (day and night) cycles of fluorescent light $\left(76 \mu \mathrm{E} \mathrm{m}^{-2} \mathrm{~s}^{-1}\right)$ for an additional 5 to 6 days until the growth of $M$. oryzae was approximately $50 \mathrm{~mm}$ in diameter. The Parafilm was then removed and the culture plates were incubated for an additional 10 days to induce sporulation. Conidia were harvested by adding $5 \mathrm{ml}$ of distilled water to each culture plate, scraping the surface of the fungal colony with a soft brush, and filtering the suspension through four layers of cheesecloth. The final concentration of conidial suspension of each strain was adjusted to $4 \times 10^{4}$ conidia/ml using a hemacytometer. Conidia suspensions used to inoculate perennial ryegrass blades were prepared using distilled water pre-added with Tween 20 (one drop per 1,000 $\mathrm{ml}$ of distilled water).

Evaluation of viability and azoxystrobin-sensitivity stability of the wildtype and G143A resistant strains. Prior to comparing the fitness and competitive ability between the two strains, this experiment was conducted to ensure that the two strains were equally viable and consistent in their sensitivity to azoxystrobin.

Half-strength PDA amended with technical grade azoxystrobin (Syngenta Crop Protection, Greensboro, NC) at $1 \mu \mathrm{g} / \mathrm{ml}$ dissolved in acetone was used to detect resistant conidia (27); nonfungicideamended medium was used to determine the total number of germinated conidia. Salicylhydroxamic acid (SHAM) was dissolved in methanol and added to both azoxystrobin-amended and nonfungicideamended media to inhibit the alternative respiratory pathway (16). The final concentrations of SHAM, acetone, and methanol were $100 \mu \mathrm{g} / \mathrm{ml}, 1,000 \mu \mathrm{g} / \mathrm{ml}$, and $1,000 \mu \mathrm{g} / \mathrm{ml}$, respectively. Conidial suspensions of the wild-type strain and resistant mutant $(50 \mu \mathrm{l}$ each) were pipetted onto the nonfungicide-amended and azoxystrobin-amended media, spread with a sterile glass rod, and allowed to dry before closing the plate. There were two replicates (plates) for each medium. The plates were incubated at $23^{\circ} \mathrm{C}$ for 16 to $24 \mathrm{~h}$ and then examined under the microscope. A conidium was scored as germinated if a normal-appearing germ tube was at least the length of the conidium (20). Germination rate (percent) was determined by recording the number of germinated conidia out of 50 to 70 randomly selected conidia. Viability of the conidia was measured by the germination rate on nonfungicideamended media. Azoxystrobin-sensitivity stability is the consistency in expressing the sensitivity to azoxystrobin, which was determined by comparing the germination rates on nonfungicide-amended media and azoxystrobin-amended media for each strain. This experiment was repeated four times.

Fitness comparison of the wild-type and G143A resistant strains. Perennial ryegrass leaves were collected by clipping 6-week-old plants $2 \mathrm{~cm}$ above the soil line, and then were cut into 5-cm-long segments for a detached-leaf assay. The inoculation was conducted by immersing leaf blade segments into 50-ml centrifuge tubes containing $20 \mathrm{ml}$ of conidial suspensions of the wild-type strain or the resistant mutant, and shaken for approximately $10 \mathrm{~s}$. Leaf blades used as controls were inoculated with $20 \mathrm{ml}$ of sterile water. Leaf blades were removed from the vials and placed on sterilized paper towels in a laminar flow hood to remove excessive water from leaf surface. In total, 10 leaf blades were placed in petri dishes containing $1.5 \%$ water agar ( $7.5 \mathrm{~g}$ of Difco granulated agar in $500 \mathrm{ml}$ of distilled water), sealed with Parafilm, and incubated at $28^{\circ} \mathrm{C}$ under 12 $\mathrm{h}$ (day/night) cycles of fluorescent light (76 $\mu \mathrm{E} \mathrm{m}^{-2} \mathrm{~s}^{-1}$ ) in a controlled environmental chamber. There were four replications (a petri dish per replication) for each strain.

Leaf blades showing symptomatic gray leaf spot lesions were evaluated for disease severity (0-to-10 scale; $0=$ leaf asymptomatic, $1=1$ to 10 and $10=91$ to $100 \%$ leaf area necrotic) 6 days after inoculation and used to determine the virulence of the strains. Relative secondary inoculum production was used as the second fitness parameter in this study. To harvest secondary inoculum, leaf blades with symptomatic gray leaf spot lesions from one petri dish (one replication) were placed into a filtra bag (LABPLAS, Sainte-Julie, Canada), $10 \mathrm{ml}$ of sterilized water was added to each bag, and bags were placed in a stomacher (MiniMix; Interscience, Weymouth, MA) at medium speed set for 1 min to dislodge conidia from lesions. The number of conidia was counted using a hemacytometer. Relative secondary inoculum production was calculated by dividing the number of conidia harvested by the mean of disease severity of blades from one petri dish. This experiment was repeated eight times and data were combined for analysis.

Competitive ability of the G143 resistant mutant in the absence of fungicide in mixed populations. Three mixed populations with ratios of 10:90 for the resistant mutant (R) and wild-type strain (S), 20R:80S, and 50R:50S were used as initial inocula. Mixed populations were prepared by mixing appropriate volumes of conidial suspensions of the resistant mutant and wild-type strain at a concentration of $4 \times$ $10^{4}$ conidia/ml to produce the ratios in the combination.

Inoculation of detached leaves, collection of conidia from the infected leaves, and in vitro germination assays determining conidial sensitivity were performed following the same procedure described previously. The percent conidia after infection was calculated by: percent resistant conidia $=[(\mathrm{A} / \mathrm{B}) /(\mathrm{C} / \mathrm{D})] \times 100 ;$ percent sensitive conidia $=100-($ percent resistant conidia); where $\mathrm{A}=$ the number of conidia germinated on azoxystrobin-amended medium, $\mathrm{B}=$ the total number of conidia counted on azoxystrobin-amended medium, $\mathrm{C}=$ the number of conidia germinated on nonfungicide-amended medium, and $\mathrm{D}=$ the total number of conidia counted on nonfungicide-amended medium. B and D may be different due to the availability of conidia on the plates counted. (A/B) calculated the germination rate of resistant conidia of all the conidia 
harvested because azoxystrobin-amended medium allows only the conidia of resistant strain to germinate. (C/D) calculated the germination rate of all conidia harvested because both strains germinate equally well on nonfungicide-amended medium. Therefore, $\{[(\mathrm{A} / \mathrm{B}) /(\mathrm{C} / \mathrm{D})] \times$ $100\}$ represented the percentage of resistant conidia (not the percentage of germinated resistant conidia) in the conidia harvested. The ratios of wild-type strain conidia to resistant conidia after infection were compared with the initial ratios of the inocula. The experiment was repeated eight times and data were combined for analysis.

Effects of fungicide on an initial population containing $5 \%$ G143A resistant mutant. The following formulated fungicides were used according to the highest label rate for gray leaf spot control to make fungicide suspensions of $100 \mathrm{ml}$ using distilled water: azoxystrobin (A) $0.15 \mathrm{~g}$ of product), chlorothalonil (C) (Daconil Ultrex WDG; Syngenta Crop Protection, $1.4 \mathrm{~g}$ of product), mancozeb (M) (Fore WSP; Dow AgroScience LLC, Indianapolis, IN, $3 \mathrm{~g}$ of product), propiconazole (P) (Banner Maxx MEC; Syngenta Crop Protection, $0.8 \mathrm{ml}$ of product), and thiophanate-methyl (T) (3336F; Cleary Chemical Corporation, Dayton, NJ, $2.3 \mathrm{ml}$ of product). Six half-rate mixtures were prepared accordingly as $1 / 2 \mathrm{~A}+1 / 2 \mathrm{C}$, $1 / 2 \mathrm{~A}+1 / 2 \mathrm{M}, \quad 1 / 2 \mathrm{P}+1 / 2 \mathrm{C}, \quad 1 / 2 \mathrm{P}+1 / 2 \mathrm{M}, \quad 1 / 2 \mathrm{~T}+1 / 2 \mathrm{C}$, and $1 / 2 T+1 / 2 M$. Perennial ryegrass leaf blade segments, prepared as described previously, were immersed into 50-ml centrifuge tubes containing $30 \mathrm{ml}$ of fungicide suspension or deionized water and shaken gently for approximately $10 \mathrm{~s}$. Treated blades were placed on a paper towel in a fume hood for $15 \mathrm{~min}$, allowed to dry, and then placed in sealed plastic bags. Six hours after treatment, 10 blades from each treatment were placed on a moist filter paper in a 100-by-15-mm petri dish. There were four replications (a petri dish per replication) of treatments.

The mixed population of $M$. oryzae with $5 \%$ of resistant mutant was used to inoculate the blades that were treated with fun(Heritage WG; Syngenta Crop Protection,

gicides. The conidial suspension was applied to the detached leaves using an atomizer ( $4 \mathrm{ml} /$ plate), and the petri dishes were placed in a controlled environment chamber under a 12-h period of fluorescent light $\left(155 \mu \mathrm{E} \mathrm{m}^{-2} \mathrm{~s}^{-1}\right)$ at $28^{\circ} \mathrm{C}$ and 90 to $100 \%$ relative humidity. The petri dishes were arranged in a completely randomized design. Disease severity assessments and quantification of conidia of the wild-type strain and resistant mutant were conducted following the procedure described previously. The experiment was repeated four times.

Data analysis. The two-sample $t$ test was used for the comparisons between wild-type and resistant strains on viability, azoxystrobin-sensitivity stability, disease severity, and relative secondary inoculum production (Minitab, V. 14; Minitab Inc., State College, PA). Analysis of variance was conducted using PROC GLM to estimate the ratio effects of wild-type and resistant strains in the initial inocula on the composition of the conidia harvested after infection occurred (SAS 9.1; SAS Institute, Cary, NC). The two-sample $t$ test was used to compare azoxystrobin sensitivity of recovered conidia on nonfungicideamended and azoxystrobin-amended medium (Minitab Inc.).

\section{RESULTS}

Evaluation of viability and azoxystrobin-sensitivity stability of the wildtype and G143A resistant strains. Both strains of $M$. oryzae demonstrated high viability on nonfungicide-amended media, with over $85 \%$ of germinations on nonamended media. Both strains also expressed consistent responses to azoxystrobin across four experiments because there was no germination of conidia of the wild-type strain on azoxystrobin-amended medium, and conidia produced by the resistant mutant germinated equally well on azoxystrobin-amended media (Table 1).

Fitness comparison of the wild-type and G143A resistant strains. Six days after inoculation, control blades which were inoculated with sterile water remained green and intact. Characteristic gray leaf spot symptoms developed on

Table 1. Comparison of the viability and azoxystrobin sensitivity stability of an azoxystrobin wildtype strain and a G143A resistant mutant of Magnaporthe oryzae

\begin{tabular}{|c|c|c|c|c|}
\hline \multirow[b]{3}{*}{ Strain } & \multicolumn{4}{|c|}{ Germination rate $(\%)^{x}$} \\
\hline & \multicolumn{2}{|c|}{ Non-fungicide-amended media } & \multicolumn{2}{|c|}{ Azoxystrobin-amended medium } \\
\hline & Range & Mean & Range & Mean \\
\hline Wild-type & $84-97$ & $89 \mathrm{a}$ & 0 & $0 \mathrm{~b}$ \\
\hline Resistant & $81-95$ & $88 \mathrm{a}$ & $83-97$ & $89 \mathrm{a}$ \\
\hline
\end{tabular}

${ }^{x}$ Germination rate on nonfungicide-amended media measures the viability of the strains and on azoxystrobin-amended medium measures azoxystrobin sensitivity. Means followed by a different letter in the same column are significantly different according to a two-sample $t$ test $(P \leq 0.05)$.

${ }^{y}$ Nonfungicide-amended media contains salicylhydroxamic acid (SHAM) at $100 \mu \mathrm{g} / \mathrm{ml}$, acetone at $1,000 \mu \mathrm{g} / \mathrm{ml}$, methanol at $1,000 \mu \mathrm{g} / \mathrm{ml}$, and no azoxystrobin.

${ }^{\mathrm{z}}$ Azoxystrobin-amended medium contains azoxystrobin at $1 \mu \mathrm{g} / \mathrm{ml}$, SHAM at $100 \mu \mathrm{g} / \mathrm{ml}$, acetone at $1,000 \mu \mathrm{g} / \mathrm{ml}$, and methanol at $1,000 \mu \mathrm{g} / \mathrm{ml}$. perennial ryegrass blades inoculated with the wild-type or resistant strain of $M$. oryzae. Disease severity of the wild-type strain was significantly higher $(P \leq 0.05)$ than that of the resistant mutant. However, there was significantly greater relative secondary inoculum produced on the necrotic lesions caused by the resistant mutant than that by the wild-type strain (Table 2).

Competitive ability of G143A resistant mutant in the absence of fungicide. The number of conidia produced on symptomatic leaves from ratio treatments of 10R:90S, 20R:80S, and 50R:50S was not significantly different, with means of 56 , 64, and 41 per filtra bag, respectively $(P \leq$ 0.05) (Fig. 1). In the absence of fungicide, conidia harvested after infection contained significantly less resistant conidia compared with that in the initial mixture of inocula. Less than a third of the conidia were resistant compared with those in the initial inocula in all three ratio treatments (Fig. 2A). A reversed trend was observed with the sensitive conidia. The compositions of the sensitive conidia in total conidia harvested after infection occurred increased in all three ratio treatments (Fig. 2B). The initial ratios of 90S:10R, 80S:20R, and 50S:50R evolved into 97S:3R, 96S:4R, and 84S:16R after infection had occurred.

Effect of fungicides on an initial population containing 5\% G143A resistant mutant. Among the treatments of five fungicides and six mixtures, the disease developed only on the control blades treated with deionized water and those treated with azoxystrobin. Mean disease severity in the control blades $(=5)$ was significantly $(P \leq 0.05)$ higher than that in azoxystrobin-treated blades $(=1)$. All conidia collected from symptomatic controls were sensitive to azoxystrobin because there was $80 \%$ germination on nonfungicide-amended media and no germination on azoxystrobin-amended media. In contrast, all conidia collected from azoxystrobin-treated plants were resistant to

Table 2. Comparison of disease severity and relative secondary inoculum production between an azoxystrobin wild-type strain and a G143A resistant mutant of Magnaporthe oryzae on perennial ryegrass blades

\begin{tabular}{lcc}
\hline Strain & Severity $^{\mathbf{y}}$ & Inoculum $^{\mathbf{z}}$ \\
\hline Wild-type & $8 \mathrm{a}$ & $6 \mathrm{a}$ \\
Resistant & $6 \mathrm{~b}$ & $13 \mathrm{~b}$ \\
\hline
\end{tabular}

y Disease severity is based on an index of a 0-to10 scale, where $0=$ leaf asymptomatic and 10 $=>90 \%$ leaf area necrotic. Means of disease severity followed by a different letter are significantly different according to a two-sample $t$ test $(P \leq 0.05)$.

${ }^{\mathrm{z}}$ Relative secondary inoculum production = number of conidia washed/mean of disease severity. Means of relative secondary inoculum production followed by different letter are significantly different according to a twosample $t$ test $(P \leq 0.05)$. 
azoxystrobin, with mean germination rates of 87 and $88 \%$ on nonfungicide-amended and azoxystrobin-amended media, respectively. There was no gray leaf spot symptom development on leaves treated with chlorothalonil, mancozeb, propiconazole, thiophanate-methyl, or half-rate mixtures of azoxystrobin, propiconazole, and thiophanate-methyl with either chlorothalonil or mancozeb.

\section{DISCUSSION}

To our knowledge, this is the first study to investigate the competitive ability of a field G143A azoxystrobin-resistant mutant of $M$. oryzae in the gray leaf spot pathosystem. Three ratio treatments in the competitive ability study, 10R:90S, 20R:80S, and 50R:50S, were selected to represent a trace, a small portion, and half of a population becoming resistant to azoxystrobin. A population with the situation where the resistance is dominant was not investigated in this study because earlier stages during a resistance build-up are more meaningful from a practical resistance management standpoint. The detached leaf assay provided important information on the dynamics of azoxystrobin resistance. This method allows strict partitioning of the treatments (single petri dishes in this study), therefore avoiding crosscontamination, which has been a problem in several studies reported previously $(15,19)$. Detached leaf assays in this study provided an advantage over entire plants in pots with regard to practical application of the experimental procedure that is more suitable for leaves in petri plates. Additionally, it also provided greater control of environmental conditions and a higher repeatability of the experiments. For those benefits, detached leaf assays have been used in various studies, such as of pathogenicity in Phytophthora spp.(18), virulence in $M$. grisea $(1,4)$, fungicide resistance in Botrytis cinerea (26), fungicide sensitivity in $P$. viticola and Uncinula necator (Schwein.) Burrill $(29,30)$, and several others.

The separate infections of perennial ryegrass leaves by the wild-type and resistant strains, as performed in the fitness test, showed that the resistant strain produced greater secondary inocula than the wild-type. However, the simultaneous infection of the leaves by the two strains in the absence of fungicide resulted in the increases of wild-type conidia and the decrease of the resistant conidia in all three ratio treatments. This clearly indicates that, when two strains coexist, there is a competitive advantage of the wild-type strain over the resistant mutant within the environment tested, which is also a favorable condition for disease development in the field. M. oryzae is a strong asexually reproduced fungus; though it is known to be capable of undergoing a parasexual cycle and other types of genetic recombination, such as gene flow, those usually take place in a population level over a long period of time (31). Given the small population and only 6 days of a coexistence period as tested in this study, the influence from such recombination on the ratio composition of conidia harvested should be minimal. Less competitive ability of the resistant mutant during co-infection with the wild-type in the absence of fungicide, as found in this research, indicates that the resistant mutant may suffer some reduction in fitness. Fitness costs associated with resistance genes are important from an evolutionary perspective because they allow selection against resistance in the absence of the fungicide, leading to a decrease in the frequency of resistant genes in the pathogen population $(6,8,9)$. Some examples are the decline of resistance in populations of $B$. cinerea to dicarboximides, Cercospora beticola Sacc. to demethylation inhibitors, and $M$. oryzae to kasugamycine in the field $(14,24,25)$. Furthermore, mixtures or alternations with fungicides of different modes of action could institute the delay of the selection for fungicide resistance $(17,23)$.

This study also showed that applications of fungicides with different modes of action or mixtures, which included half-rate mixtures of azoxystrobin with contact fungicides, eliminated $5 \%$ of the resistant mutant in the population. Based on the above results, azoxystrobin resistance management may be able to utilize the weaker competitive ability or fitness penalties of the resistant mutant, and use mixtures and alternations may be worthy of further investigation as practical solutions to tackle the resistance population.

In a practical disease management situation, complete coverage of plants with fungicide will seldom occur when the crop is sprayed. Therefore, complete eradication of the resistant mutant may not be achieved from one application of alternative fungicides or mixtures, as demonstrated in this study. Employing a posttreatment monitoring program could determine whether the management strategies are effective or whether the use of azoxystrobin should be avoided. In a study, the resumption of ethirimol use for controlling barley mildew (Blumeria graminis f. sp hordei) is a successful example of post-treatment monitoring (6). Conducting a post-treatment monitoring program in areas where azoxystrobin failed would be meaningful in sustaining the fungicide use.

This study was conducted under growth chamber conditions by using a resistant and a wild-type strain to demonstrate the fitness and competitive ability of the

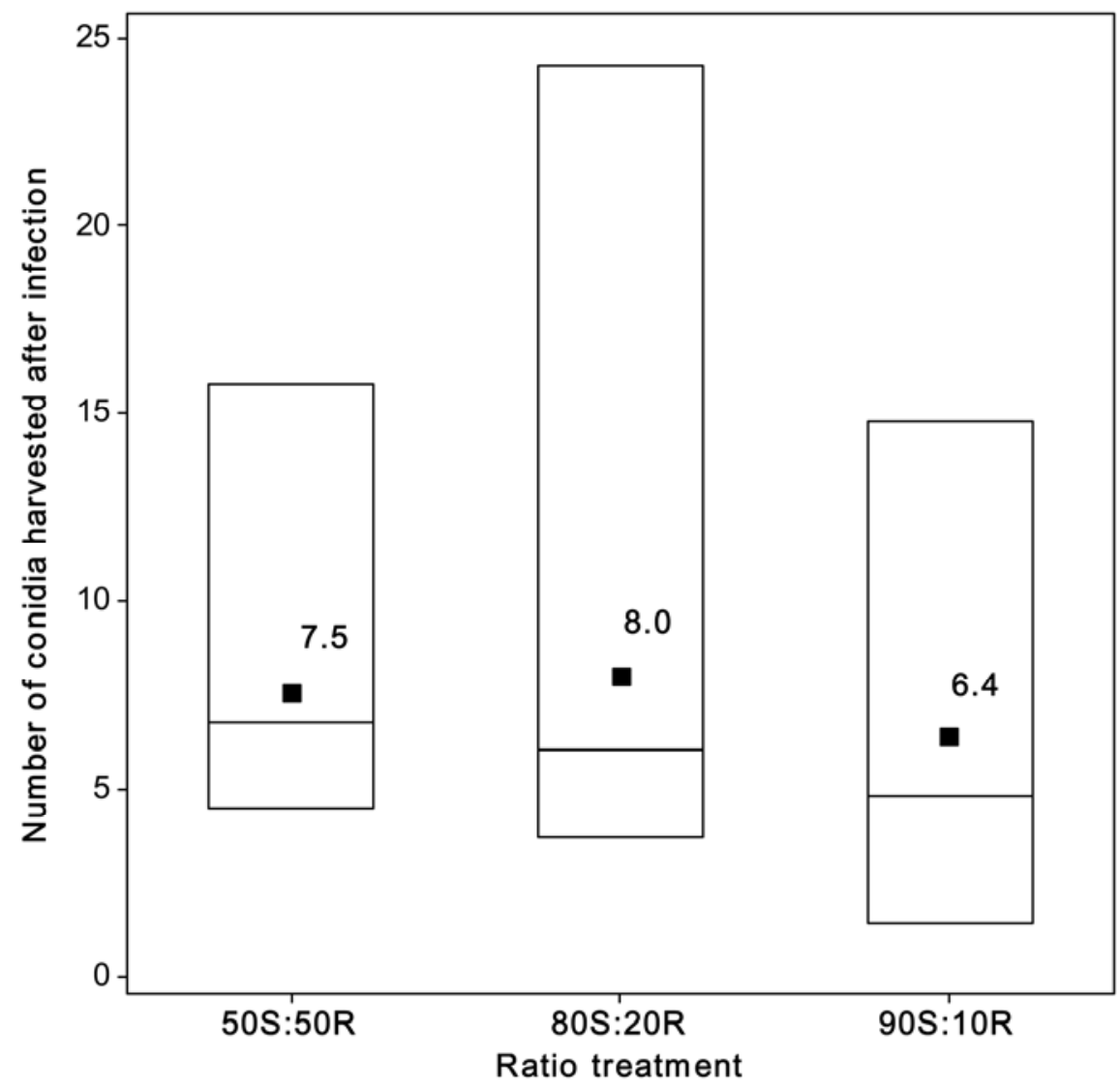

Fig. 1. Boxplot of total number of conidia (square root transformed) of Magnaporthe oryzae harvested from the infections caused by initial inocula in ratios of 50S:50R, 80S:20R, and 90S:10R; S represents azoxystrobin wiild-type strain and $\mathrm{R}$ represents azoxystrobin-resistant mutant G143A. Means are indicated by solid squares. 
strains. Because QoI fungicides are highly effective against $M$. oryzae, turf managers are likely to continue using azoxystrobin to manage gray leaf spot; therefore, the risk for resistance development in the pathogen population remains a major concern. Significant findings in this study warrant extended surveys to identify resistant strains
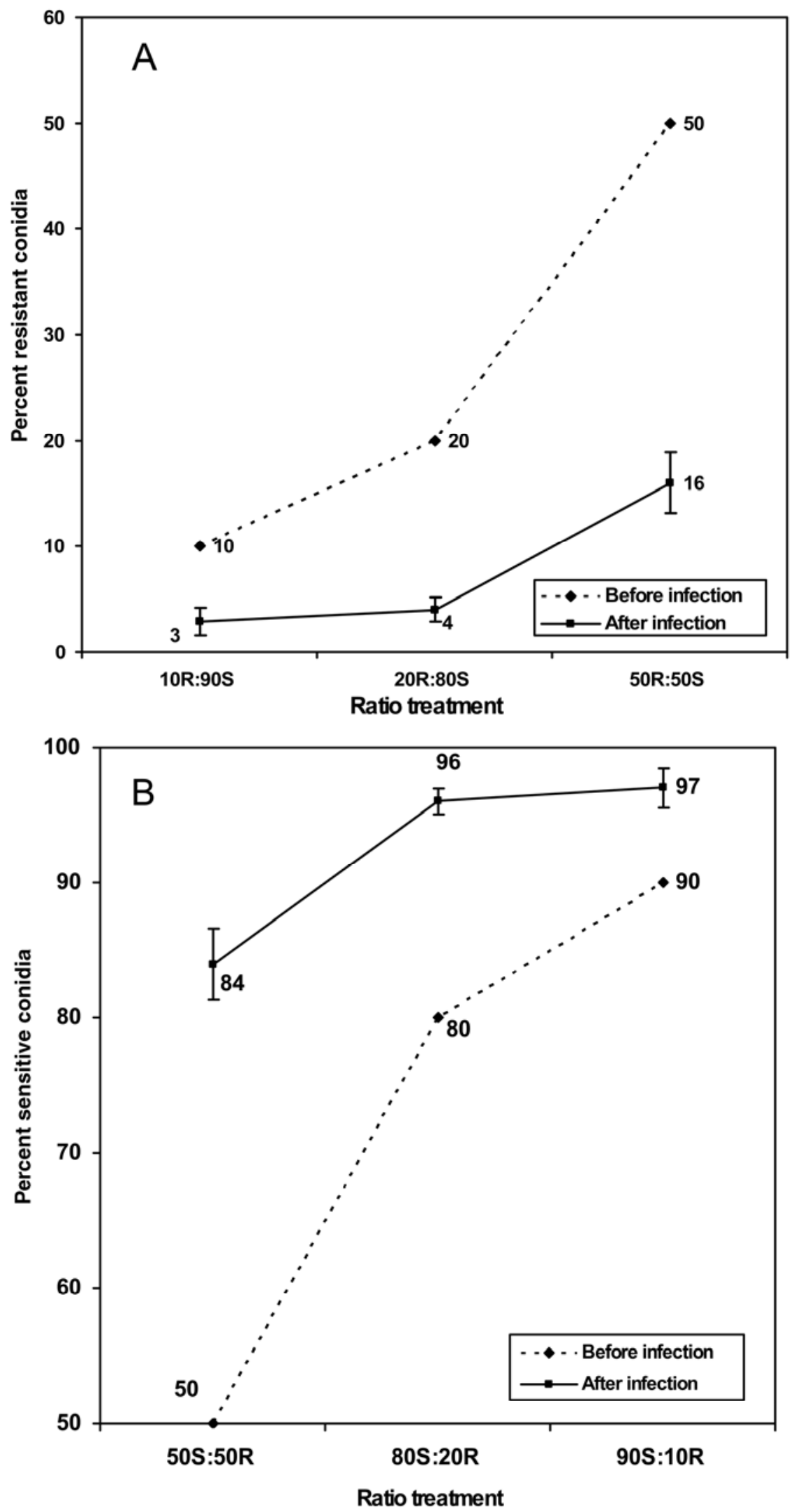

Fig. 2. Comparison of the percentage of an azoxystrobin wild-type (S) and a G143A resistant mutant (R) of Magnaporthe oryzae before and after infection in mixed populations. A, Resistant mutant and B, wild-type strain. Standard error bars are indicated on the graph.

in the northeastern United States and test their fitness and competitive ability with the wild-type strains in the gray leaf spot pathosystem. Additionally, other fitness parameters such as survival rate during overwintering and infection efficiencies of secondary inoculum will provide further insights into fitness and competitive ability of the mutants of M. oryzae.

\section{ACKNOWLEDGMENTS}

Financial support for this study was provided by the Pennsylvania Turfgrass Council and Syngenta Crop Protection. We thank M. Nita for providing assistance in this study and G. Moorman and L. Tredway for critically reviewing the manuscript.

\section{LITERATURE CITED}

1. Avila-Adame, C., and Köller, W. 2002. Disruption of the alternative oxidase gene in Magnaporthe grisea and its impact on host infection. Mol. Plant-Microbe Interact. 15:493-500.

2. Avila-Adame, C., and Köller, W. 2003. Characterization of spontaneous mutants of Magnaporthe grisea expressing stable resistance to the Qo-inhibiting fungicide azoxystrobin. Curr. Genet. 42:332-338.

3. Avila-Adame, C., and Köller, W. 2003. Impact of alternative respiration and target-site mutations on responses of germinating conidia of Magnaporthe grisea to Qo-inhibiting fungicides. Pest Manage. Sci. 59:303-309.

4. Balhadère, P. V., Foster, A. J., and Talbot, N. J. 1999. Identification of pathogenicity mutants of the rice blast fungus Magnaporthe grisea by insertional mutagenesis. Mol. Plant-Microbe Interact. 12:129-142.

5. Bierman, S., Fitt, B., Van Den Bosch, F., Bateman, G., Jenkyn, J., and Welham, S. 2002. Changes in populations of Tapesia yallundae and Tapesia acuformis (eyespot) under different fungicide regimes in successive crops of winter wheat 1984-2000. Plant Pathol. 51:191201.

6. Brent, K. J. 1995. Fungicide resistance in crop pathogens: How can it be managed? Fungicide Resistance Action Committee Monograph No. 1. Groupment Int. Assoc. Nat. Fabricants Prodvits Agrochemiques, Brussels.

7. Chin, K. M., Chavaillaz, D., Kaesbohrer, M., Staub, T., and Felsenstein, F. G. 2001. Characterizing resistance risk of Erysiphe graminis $\mathrm{f}$. sp. tritici to strobilurins. Crop Prot. 20:87-96.

8. Dekker, J. 1982. Can we estimate the fungicide-resistance hazard in the field from laboratory and greenhouse tests? Pages 128-139 in: Fungicide Resistance in Crop Protection. J. Dekker and S. G. Georgopoulos, eds. Cent. Agric. Publ. Doc., Wageningen, The Netherlands.

9. Fry, W. E., and Milgroom, M. G. 1990. Population biology and management of fungicide resistance. Pages 275-285 in: Managing Resistance to Agrochemicals: From Fundamental Research to Practical Strategies, M. B. Green, W. K. Moberg, and H. LeBaron, eds. Am. Chem. Soc. Symp. Ser. No. 421.

10. Gisi, U., Sierotzki, H., Cook, A., and McCaffery, A. 2002. Mechanisms influencing the evolution of resistance to Qo inhibitor fungicides. Pest Manage. Sci. 58:859-867.

11. Gubbins, S., and Gilligan, C. A. 1999. Invasion thresholds for fungicide resistance: deterministic and stochastic analyses. Proc. R. Soc. Lond. Ser. B 266:2539-2549.

12. Heaney, S., Hall, A., Davies, S., and Olaya, G. 2000. Resistance to fungicides in the QolSTAR cross-resistance group: Current perspectives. Proc. 2000 BCPC Conf. Pests Dis. 2:755-762.

13. Jordan, D. B., Livingston, R. S., Bisaha, J. J., Duncan, K. E., Pember, S. O., Picollelli, M. A., 
Schwartz, R. S., Sternberg, J. A., and Tang, X. S. 1999. Mode of action of famoxadone. Pestic. Sci. 55:105-118.

14. Karaoglanidis, G. S., Thanassoulopoulos, C. C., and Ioannidis, P. M. 2001. Fitness of Cercospora beticola field isolates resistant and sensitive to demethylation inhibitor fungicides. Eur. J. Plant Pathol. 107:337-347.

15. Katan, T., and Ovadia, S. 1985. Effect of chlorothanlonil on resistance of Botrytis cinerea to dicarboximide in cucumber glasshouses. EPPO Bull. 15:365-369.

16. Köller, W., Avila-Adame, C., Olaya, G., and Zheng, D. 2001. Resistance to strobilurin fungicides. Pages 215-229 in: Agrochemical Resistance-Extent, Mechanism, and Detection. J. M. Clark and I. Yamaguchi, eds. American Chemical Society.

17. Köller, W., and Scheinpflug, H. 1987. Fungal resistance to sterol biosynthesis inhibitors: a new challenge. Plant Dis. 71:1066-1074.

18. Moralejo, E., Belbahri, L., Calmin, G., GarciaMunoz, J. A., Lefort, F., and Descals, E. 2008. Strawberry tree blight in Spain, a new disease caused by various Phytophthora species. J. Phytopathol. 156:577-587.

19. Northover, J. 1988. Persistence of dicarboximide-resistant Botrytis cinerea in Ontario vineyards. Can. J. Plant Pathol. 10:123-132.

20. Olaya, G., Zheng, D., and Köller, W. 1998.
Differential responses of germinating Venturia inaequalis conidia to kresoxim-methyl. Pestic. Sci. 54:230-236.

21. Parnell, S., Gilligan, C. A., and Van den Bosch, F. 2005. Small-scale fungicide spray heterogeneity and the coexistence of resistant and sensitive pathogen strains. Phytopathology 95:632-639.

22. Peever, T. L., and Milgroom, M. G. 1995. Fungicide resistance: lessons for herbicide resistance management. Weed Technol. 9:840849.

23. Skylakakis, G. 1987. Changes in the composition of pathogen population caused by resistance to fungicides. Pages 227-237 in: Populations of Plant Pathogens: Their Dynamics and Genetics. M. S. Wolfe and C. E. Caten, eds. Blackwell Scientific Publications, Oxford.

24. Staub, T. 1991. Fungicide resistance: practical experience with anti-resistance strategies and the role of integrated use. Annu. Rev. Phytopathol. 29:421-442.

25. Uesugi, Y 1982. Pyricularia oryzae of rice. Pages 207-218 in: Fungicide Resistance in Crop Protection. J. Dekker and S. G. Georgopoulos, eds. Cent. Agric. Publ. Doc., Wageningen, The Netherlands.

26. Vali, R. J., and Moorman, G. W. 1992. Influence of selected fungicide regimes on frequency of dicarboximide-resistant and dicar- boximide-sensitive strains of Botrytis cinerea. Plant Dis. 76:919-924.

27. Vincelli, P., and Dixon, E. 2001. Resistance to QoI fungicides in gray leaf spot. Golf Course Manage. 69:49-53.

28. Vincelli, P., and Dixon, E. 2002. Resistance to $\mathrm{Q}(\mathrm{o}) \mathrm{I}$ (strobilurin-like) fungicides in isolates of Pyricularia grisea from perennial ryegrass. Plant Dis. 86:235-240.

29. Wong, F. P., and Wilcox, W. F. 2000. Distribution of baseline sensitivities to azoxystrobin among isolates of Plasmopara viticola. Plant Dis. 84:275-281.

30. Wong, F. P., and Wilcox, W. F. 2002. Sensitivity to azoxystrobin among isolates of Uncinula necator: baseline distribution and relationship to myclobutanil sensitivity. Plant Dis. 86:394404.

31. Zeigler, S. R. 1998. Recombination in Mag naporthe grisea. Annu. Rev. Phytopathol. 36:249-275.

32. Zheng, D., Olaya, G., and Köller, W. 2000 Characterization of laboratory mutants of Venturia inaequalis resistant to the strobilurinrelated fungicide kresoxim-methyl. Curr Genet. 38:148-155.

33. Ziogas, B., Markoglou, A., and Tzima, A. 2002. A non-Mendelian inheritance of resistance to strobilurin fungicides in Ustilago maydis. Pest Manage. Sci. 58:908-916. 